\title{
Fish Slaughter, Killing, and Euthanasia: A Review of Major Published U.S. Guidance Documents and General Considerations of Methods ${ }^{1}$
}

Roy P.E. Yanong, Kathleen H. Hartman, Craig A. Watson, Jeffrey E. Hill, B. Denise Petty, and Ruth Francis-Floyd $^{2}$

\section{Introduction}

Fish are important to society for a number of different positive uses: for food, for recreation, for research, and as pets. However, non-native fish illegally released into the environment pose a nuisance. In each case, death of fish may be necessary or desirable. Cultural and ethical norms for causing death of fish reflect differing human perceptions according to the circumstances. There is an ongoing scientific debate regarding how fish process negative stimuli, specifically, whether they feel pain in the same or an equivalent manner as do mammals. This debate will not be resolved easily. Ultimately, science will only provide part of the answer. Differing circumstances and societal values will also be important in determining how fish are handled in each situation. Parallels can be drawn with societal considerations of terrestrial species. For example, in research, mice and rats are important laboratory animals; to some, they are valuable pets; however, in other situations, they are unwanted pests, for which a variety of legal control methods are available. Methods used to cause death of fish should, as much as practical, seek to "1) minimize stress and 2) minimize time to death" (Hartman 2006).

The terminology used to describe the deliberate ending of the life of a fish is largely based on the contextual application of the activity (Table 1). Three main categories used to describe ending the life of a fish are slaughter, killing, and euthanasia. The term slaughter is used primarily by agricultural producers and commercial fishers for products intended for human consumption (e.g., agricultural harvest, commercial fisheries). The term killing is used to describe some recreational fishing practices and may also include activities such as fish sampling, depopulation or eradication, and control. These words are all used to describe activities by field personnel, resource managers, and veterinarians or fish health specialists for ecological research, fish

1. This document is CIR1525, one of a series of the Fisheries and Aquatic Sciences Department, Florida Cooperative Extension Service, Institute of Food and Agricultural Sciences, University of Florida. Original publication date June, 2007. Visit the EDIS Web Site at http://edis.ifas.ufl.edu.

2. Roy P.E. Yanong is associate professor and extension veterinarian, Kathleen H. Hartman is courtesy assistant professor, Craig A. Watson is assistant director of aquaculture programs, and Jeffrey E. Hill is assistant professor, Tropical Aquaculture Laboratory-Ruskin, Department of Fisheries and Aquatic Sciences; B. Denise Petty is clinical assistant professor and extension veterinarian, and Ruth Francis-Floyd is professor and director of aquatic animal health, Department of Fisheries and Aquatic Sciences, and Large Animal Clinical Sciences; Florida Cooperative Extension Service, Institute of Food and Agricultural Sciences.

The Institute of Food and Agricultural Sciences (IFAS) is an Equal Opportunity Institution authorized to provide research, educational information and other services only to individuals and institutions that function with non-discrimination with respect to race, creed, color, religion, age, disability, sex, sexual orientation, marital status, national origin, political opinions or affiliations. U.S. Department of Agriculture, Cooperative Extension Service, University of Florida, IFAS, Florida A. \& M. University Cooperative Extension Program, and Boards of County Commissioners Cooperating. Larry Arrington, Dean 
Table 1. Terminology used to describe the deliberate ending of the life of fish

\begin{tabular}{|c|c|c|}
\hline Term & Possible Applications & Examples \\
\hline Slaughter & $\begin{array}{l}\text { o Agricultural harvest } \\
\text { o Commercial fisheries }\end{array}$ & $\begin{array}{l}\text { o Catfish, salmon, and tilapia } \\
\text { o Wild-caught grouper and snapper catches }\end{array}$ \\
\hline Euthanasia & $\begin{array}{l}\text { o Pets } \\
\text { o High-value wildlife or zoo animals }\end{array}$ & $\begin{array}{l}\text { o Hobbyist koi and goldfish } \\
\text { o Public aquarium shark }\end{array}$ \\
\hline
\end{tabular}

${ }^{1}$ Spring viremia of carp (SVC) and viral hemorrhagic septicemia (VHS) are viral diseases, that are under international and national regulatory control and for which depopulation of infected populations is warranted.

health inspections, or to eliminate unwanted fish (including diseased or non-native fish) from a water body. The term harvest specifically refers to the act or process of gathering a crop, for example, as in aquaculture and commercial fishing; however, harvest may also be used to describe fish removed from a water body by anglers. As described above, harvested fish may be slaughtered or killed, depending upon the context of the activity. The term euthanasia (meaning an easy or good death) is typically used by veterinarians and laboratory research scientists to describe ending the life of a pet, research animal, or other high-value (financial or sentimental) fish (e.g., public aquarium fish) (Hartman 2006).

\section{Available Guidance Documents from Different Organizations and Agencies}

Four major guidance documents currently available in the U.S. will be discussed in this publication: 1) JSA Guide to Drug, Vaccine, and Pesticide Use in Aquaculture; 2) Use of Fishes in Research Committee's Guidelines for the Use of Fishes in Research; 3) Guide to the 2000 Report of the AVMA Panel on Euthanasia; and 4) AAZV's Guidelines for Euthanasia of Nondomestic Animals. Each document has a specific target audience, and contains useful information, but also has limitations.

\section{JSA Guide to Drug, Vaccine, and Pesticide Use in Aquaculture}

The Federal Joint Subcommittee on Aquaculture (JSA) Working Group on Quality Assurance in Aquaculture Production's Guide to Drug, Vaccine, and Pesticide Use in Aquaculture (April 2007 revision) is an important guidance document for aquaculture and for use of specific aquatic-site labeled products. The entire document is available on the Web as an html Web page http://aquanic.org/jsa/wgqaap/drugguide/ drugguide.htm. This document was produced collaboratively by the US Department of Agriculture (USDA-APHIS and USDA-CSREES), US Department of Health and Human Services (FDA-CVM and FDA-CFSAN), and the US EPA (Office of Pesticide Programs). The JSA Guide emphasizes the importance of knowing who the regulatory agencies are and understanding and abiding by relevant legalities and restrictions when using or adding compounds/chemicals to water bodies or for treating fish. One group of chemicals, listed in the JSA Guide, includes EPA-registered and labeled fish toxicants/piscicides such as chlorine (sodium hypochlorite, calcium hypochlorite), antimycin $\mathrm{A}$, and rotenone.

\section{Limitations of the JSA Guide to Drug, Vaccine, and Pesticide Use in Aquaculture}

Although the JSA Guide provides excellent information and linkages to relevant agencies as well as specific information on drugs and chemicals available for use in aquaculture, the document does not specifically address fish slaughter, killing, or euthanasia as topic areas. Rather, it lists specific compounds that are approved for use (or considered 
low regulatory priority) by FDA as anesthetic agents or labeled by EPA as fish toxicants.

\section{UFR-C Guidelines for the Use of Fishes in Research}

The American Fisheries Society (AFS), American Institute of Fisheries Research Biologists (AIFRB), and the American Society of Ichthyologists and Herpetologists (ASIH) also provide guidance, specifically for research purposes, in their jointly developed Use of Fishes in Research Committee's $(U F R-C)$ Guidelines for the Use of Fishes in Research http://www.fisheries.org/afs/publicpolicy/ guidelines2004.pdf. These guidelines are intended to provide general recommendations to assist researchers as well as state and federal agencies, with regards to experimental design and handling of fish species.

\section{Limitations of the UFR-C Guidelines for the Use of Fishes in Research}

This document provides useful guidance. However, the "Euthanasia" section does not clearly differentiate between the activities of fish slaughter, killing and euthanasia. Within this section, methods for fish slaughter by fish processors are described and include cold or electrical shock. Pithing, spinal cord dislocation, and decapitation, if done quickly and accurately, are considered acceptable methods for euthanasia of research fish, as is use of tricaine methanesulfonate. Although these practices may be feasible for small numbers of research fish, they are often not practical for large scale field research, and these differences should be taken into consideration. In addition, tricaine methanesulfonate is FDA-approved for temporary immobilization only. Currently, there are no FDA-approved drugs for euthanasia of fish. UFR-C Guidelines suggest stunning with an electroshock followed by rapid decapitation or cold shock if large numbers of fish are collected. However, UFR-C Guidelines also provide the caveat that these methods may be impossible to implement in commonly used fish sampling with nets that collect thousands of individuals (see General Considerations and a Review of Methods Discussed).
3.Guide to the 2000 Report of the AVMA Panel on Euthanasia

The American Veterinary Medical Association's (AVMA's) Guide to the 2000 Report of the AVMA Panel on Euthanasia (hereafter, AVMA Guide) http://www.avma.org/issues/animal_welfare/ euthanasia.pdf, now also known as the AVMA Guidelines for Euthanasia http://www.avma.org/products/animal_welfare/ euthanasia.asp provides recommendations specifically for veterinarians involved with pets, research animals in controlled laboratory settings, and in other situations where euthanasia specifically, as opposed to fish slaughter or killing, is under consideration. The AVMA Guide, developed over many years and revisions, has provided a good, scientific foundation for discussions and considerations in many situations where euthanasia is necessary. The AVMA Guide is not intended for use by the general public or other persons without consultation with a veterinarian, who is then also tasked to use the document only as a guide, and to rely on his or her clinical experience and judgment to apply methods described in the AVMA Guide where appropriate. A number of acceptable methods are described in the AVMA Guide, including both chemical and physical means.

\section{Limitations of the AVMA Guide to the 2000 Report of the AVMA Panel on Euthanasia}

Because of the pivotal role that veterinarians play in the arenas of animal health and welfare, the AVMA Guide has become an important and foundational reference for many different species and scenarios requiring euthanasia. The AVMA has taken the lead in developing a thoughtful, scientifically based, and comprehensive approach to animal euthanasia, and the AVMA Guide has undergone revisions as new information emerges. The $A V M A$ Guide, therefore, is often assumed to be the only acceptable source for methods for the death of animals. However, the AVMA Guide is not intended for all persons, agencies, or organizations, and is applicable and practical under a limited set of circumstances. In fact, the AVMA's recommendations are intended for "use by members of the veterinary profession" and the "failure to list 
or recommend a means of euthanasia in this report does not categorically condemn its use." While use of the AVMA Guide is appropriate for veterinarians working with fish species in many controlled settings (e.g., clinical and laboratory environments), there are conflicts with these recommendations for veterinarians and non-veterinarians working in the field with fish (e.g., agriculture and natural resources). Many agencies attempt to use or to apply the AVMA euthanasia recommendations for fish but cannot because the recommendations are limited in scope (Hartman 2006).

As described earlier in the UFR-C Guidelines section, tricaine methanesulfonate is labeled and approved only for "temporary immobilization" and not for euthanasia. It also carries a 21-day withdrawal time which should be considered when the final disposition of the euthanized fish may result in products for human or animal consumption.

Likewise, the conditions of use for drugs considered to be low regulatory priority (LRP) by the FDA should also be observed. The use of the unapproved drug carbon dioxide is typically "for anesthetic purposes in cold, cool, and warmwater fish" rather than for euthanasia. FDA will only consider their use to be a low enforcement priority when the conditions of use are observed. The list of LRP drugs and their conditions of use are described on the FDA/CVM Web site http://www.fda.gov/cvm/Documents/LRPDrugs.pdf. Furthermore, many of the other non-LRP drugs listed in the UFR-C Guidelines are unapproved for use as euthanasia agents for fish. In addition, the $A V M A$ Guide does not specifically address slaughter or killing issues.

\section{Guidelines for Euthanasia of Nondomestic Animals (AAZV Guidelines)}

The American Association of Zoo Veterinarians (AAZV) recently published their "Guidelines for Euthanasia of Nondomestic Animals" ( $A A Z V$

Guidelines) which focuses on euthanasia of captive nondomestic species and free-ranging wildlife. This report attempts to summarize current thinking and standards and to act as a starting point for further consideration and improvement of knowledge and methods. The authors acknowledge that more research is necessary for non-mammalian vertebrates.
The AAZV Guidelines recognize that factors including fish species, numbers and size, ultimate use, environmental factors, and personnel experience and skill should be considered when determining the best method of euthanasia. The AAZV Guidelines distinguishes the differences between use of the terms slaughter, killing, and euthanasia and also discusses limitations of the AVMA Guide.

The AAZV Guidelines include a combination of standard practices used in laboratory research, aquaculture, and in fisheries work in their methods of euthanasia section, and provides a summary for each method discussed.

\section{Limitations of the Guidelines for Euthanasia of Nondomestic Animals (AAZV Guidelines)}

Although differences between underlying implications for the terms slaughter, killing and euthanasia are discussed, there is overlap of the use of these terms throughout the text, which may be confusing for some. The AAZV Guidelines author(s) have chosen to expand the definition of euthanasia to include these other terms. Rotenone and antimycin are registered by the EPA as fish toxicants (pesticides), and are not officially labeled for euthanasia. Chlorine products are also EPA-registered as fish toxicants, but these are not listed in these guidelines.

There are other interpretative issues with regard to use of certain products. For example, as discussed previously, although use of tricaine methanesulfonate is FDA approved for use in temporary immobilization, the $A A Z V$ Guidelines state that other uses are allowable according to the Animal Medicinal Drug Use Clarification Act (AMDUCA). However, extra-label drug use under AMDUCA is only allowable for therapeutic uses and under those conditions listed in the Act (21 CFR 530.2). Technically, slaughter, killing, and euthanasia are not considered therapeutic uses according to AMDUCA. In reality, all of the drugs listed also are unapproved for use as fish euthanasia drugs. Likewise, carbon dioxide is considered a low regulatory priority drug but only if used for anesthetic purposes in fish, not for euthanasia. Similarly, methods discussed for pet fish owners include unapproved uses for all of the chemicals listed. 


\section{General Considerations and a Review of Methods Discussed}

There are a number of insightful guidance documents available to help determine the best mechanism of fish slaughter, killing, or euthanasia. These and other documents are intended to serve only as guidelines, and are not the result of regulatory authority. None of these guidance documents currently addresses all imaginable situations that require fish death. Further clouding the issue, the existing patchwork of regulations and regulatory agencies that have jurisdiction in these differing situations has caused confusion regarding outcomes and intentions of fish slaughter, killing, or euthanasia among many professionals working with fish.

Because there are many different circumstances under which the death of fish may be warranted, the following practical approach is suggested. Whatever method is used, fish stress and time to death must be minimized as much as practical, and death ensured. At the same time, human safety (with regard to chemical usage and food safety) and environmental safety should be taken into consideration, as well as all local, state, and federal regulations. These suggestions are based on those described guidance documents and current information (May 2007), and changes to these suggestions may be required over time. Appropriate personnel and experts intimately involved with the specific situation and current regulations should be part of the decision-making process.

In all situations, it is important to realize that within society, interpretative differences exist between the terminology and actions involved with fish harvest/slaughter, killing, or euthanasia, and their synonyms. In addition, decision-makers must be aware of practical differences between small-scale laboratory (small closed systems, simple manipulation, controlled environmental conditions) and large-scale field scenarios (large water bodies, hundreds or thousands of fish, large fish sizes, weather and other uncontrollable elements), and must understand the different perceptions and practices associated with each scenario. In many instances, the method will be based on accepted standard practices, and decisions should include the input of those with experience in the specific field or circumstance.

Use either the AVMA Guide or the AAZV Guidelines if the methods discussed are applicable to the specific situation, e.g., for small scale laboratory studies or for veterinary euthanasia of pet fish. Work with a veterinarian, if possible, in these cases. In field situations, including research, where the recommendations of the AVMA Guide may prove impractical or do not otherwise lend themselves to the particular situation at hand (e.g., chemical residues in food/game fish; large numbers of fish or logistical considerations), consider options discussed under the $A A Z V$ Guidelines. In addition to the AVMA Guide and the AAZV Guidelines, the UFR-C Guide and the JSA Guide should be consulted, along with discussions with relevant experts. Agencies and other non-veterinary fish professionals should develop their own protocols for fish euthanasia, harvest/slaughter, or killing using the best available and legal methods. Other groups and documents may also provide reasonable approaches and methods for consideration. Many of the methods will require a certain level of expertise and training, and so may not be suitable for situations lacking appropriate expertise.

Physical methods of causing death in fish include decapitation, pithing, or stunning followed by decapitation and pithing (AVMA Guide; AAZV Guidelines); cold shock, electrical shock, stunning with electroshock followed by rapid decapitation or cold shock (UFR-C Guidelines); oxygen deprivation (de-watering) may be required for mandatory depopulation of production level-facilities (UFR-C Guide) but the UFR-C Guide does not recommend this particular method (de-watering) for research.

The JSA Guide lists the EPA-labeled fish toxicants chlorine, antimycin A, and rotenone, as described previously, for use in aquaculture for depopulation/eradication, and two of these, rotenone and antimycin A are also listed in the $A A Z V$ Guidelines. Under certain situations, if label requirements can be met for aquatic environments, use of these legal, EPA-labeled fish toxicants should be considered (see JSA Guide), and these products may be the most logical options under a variety of circumstances, including for research. 
Additional chemical methods for causing death in fish include use of tricaine methanesulfonate (AVMA Guide; UFR-C Guidelines), barbiturates, inhalant anesthetics, carbon monoxide, benzocaine hydrochloride, 2-phenoxyethanol, or carbon dioxide. However, as discussed previously, neither tricaine methanesulfonate, carbon dioxide, nor any of the other fish anesthetics mentioned in any of the documents are currently approved by the FDA for euthanasia or by the EPA for depopulation of fish.

Another important consideration is final disposition of euthanized animals. Carbon dioxide is currently the only chemical described above for which there are no food safety concerns with regard to tissue residues. Use of any of the other chemicals for euthanasia or depopulation therefore automatically prohibits entry of the fish into the food chain, either by rendering, as fish meal, or as directly consumed product.

Other institutions have developed and provided rational, alternative methods for euthanasia of small numbers of fish used in research, because of difficulties with using one or another guidance document alone. For example, one university recommends the use of a saturated solution of carbon dioxide using chemical means for release, or cooling of tropical species to $4{ }^{\circ} \mathrm{C}$, and chilling of non-tropical species in chilled salt water (at temperatures significantly less than $0{ }^{\circ} \mathrm{C}$ ) (University of Washington, 2002).

In summary, fish slaughter, killing, and euthanasia differ in their context, societal value, and methods. Available guidance documents are helpful but are limited in scope. There is no single document or list of protocols that will encompass all potential circumstances for which ending the life of fish will be necessary. Careful consideration of methodologies among stakeholders and relevant experts should include discussion of pertinent science, generally accepted practices for a given activity, specific circumstances, and applicable regulations.

\section{References}

Animal Medicinal Drug Use Clarification Act of 1994 (AMDUCA). Accessed August 20, 2007. http://www.fda.gov/cvm/amducatoc.htm
AVMA Animal Welfare Principles, Approved November 2006. Accessed August 20, 2007. http://www.avma.org/issues/policy/animal_welfare/ principles.asp

FDA-CVM. Drugs Approved for Use in Aquaculture. Accessed August 20, 2007. http://www.fda.gov/cvm/drugsapprovedaqua.htm

FDA Guidance Document 1240.4200, Low Regulatory Priority Aquaculture Drugs. http://www.fda.gov/cvm/Documents/LRPDrugs.pdf http://www.fda.gov/cvm/hydrogenperoxide.htm Both sites accessed August 20, 2007.

Guidelines for the Use of Fishes in Research, 2004. American Fisheries Society, American Institute of Fisheries Research Biologists, and American Society of Ichthyologists and Herpetologists. American Fisheries Society. Accessed August 20, 2007. http://www.fisheries.org/afs/publicpolicy/ guidelines2004.pdf

Guide to Drug, Vaccine, and Pesticide Use in Aquaculture (April, 2007 revision). Joint Subcommittee on Aquaculture Working Group on Quality Assurance in Aquaculture Production. Both sites accessed August 20, 2007. http://aquanic.org/jsa/wgqaap/drugguide/ drugguide.htm

Guide to the 2000 Report of the AVMA Panel on Euthanasia. American Veterinary Medical Association (AVMA). 2001. JAVMA 281(5): 669-696. Web version: AVMA Guidelines on Euthanasia. June 2007. Accessed August 20, 2007. http://www.avma.org/issues/animal_welfare/ euthanasia.pdf

Hartman, K.H. 2006. Fish. In: Guidelines for Euthanasia of Nondomestic Animals. American Association of Zoo Veterinarians (AAZV). 111 pp.

University of Washington Policy for the Euthanasia of Fish Species, 2002. Institutional Animal Care and Use Committee, University of Washington. Accessed August 20, 2007. http://depts.washington.edu/iacuc/policies/ fish_euthanasia.html 